\title{
BMJ Open Understanding decision making about major surgery: protocol for a qualitative study of shared decision making by high-risk patients and their clinical teams
}

\author{
Sara Shaw (D) , ${ }^{1}$ Gemma Hughes (D) , ${ }^{1}$ Tim Stephens, ${ }^{2}$ Rupert Pearse, ${ }^{3}$ \\ John Prowle, ${ }^{3}$ Richard Edmund Ashcroft (D) , ${ }^{4}$ Ester Avagliano, ${ }^{5}$ James Day, ${ }^{6}$ \\ Mark Edsell, ${ }^{5}$ Jennifer Edwards, ${ }^{7}$ Leslie Everest ${ }^{8}$
}

To cite: Shaw S, Hughes G, Stephens T, et al. Understanding decision making about major surgery: protocol for a qualitative study of shared decision making by high-risk patients and their clinical teams. BMJ Open 2020;10:e033703. doi:10.1136/ bmjopen-2019-033703

- Prepublication history and additional material for this paper are available online. To view these files, please visit the journal online (http://dx.doi. org/10.1136/bmjopen-2019033703).

Received 17 August 2019 Revised 11 March 2020 Accepted 06 April 2020
Check for updates

(C) Author(s) (or their employer(s)) 2020. Re-use permitted under CC BY-NC. No commercial re-use. See rights and permissions. Published by BMJ.

For numbered affiliations see end of article.

Correspondence to

Dr Sara Shaw;

sara.shaw@phc.ox.ac.uk

\section{ABSTRACT}

Introduction Surgical treatments are being offered to more patients than ever before, and increasingly to high-risk patients (typically multimorbid and over 75). Shared decision making is seen as essential practice. However, little is currently known about what 'good' shared decision making involves nor how it applies in the context of surgery for high-risk patients. This new study aims to identify how high-risk patients, their families and clinical teams negotiate decision making for major surgery.

Methods and analysis Focusing on major joint replacement, colorectal and cardiac surgery, we use qualitative methods to explore how patients, their families and clinicians negotiate decision making (including interactional, communicative and informational aspects and the extent to which these are perceived as shared) and reflect back on the decisions they made. Phase 1 involves video recording 15 decision making encounters about major surgery between patients, their carers/families and clinicians; followed by up to 90 interviews (with the same patient, carer and clinician participants) immediately after a decision has been made and again 3-6 months later. Phase 2 involves focus groups with a wider group of (up to 90) patients and (up to 30 ) clinicians to test out emerging findings and inform development of shared decision making scenarios ( $3-5$ summary descriptions of how decisions are made).

Ethics and dissemination The study forms the first part in a 6-year programme of research, Optimising Shared decision-maklng for high-RIsk major Surgery (OSIRIS). Ethical challenges around involving patients at a challenging time in their lives will be overseen by the programme steering committee, which includes strong patient representation and a lay chair. In addition to academic outputs, we will produce a typology of decision making scenarios for major surgery to feed back to patients, professionals and service providers and inform subsequent work in the OSIRIS programme.

\section{Strengths and limitations of this study}

- New study focused on decision making about major surgery with high-risk patients.

- Novel qualitative design, combining video recording of decisionmaking encounters, with individual and group interviews.

- Guided by theory, which recognises that decisions about surgery rarely occur at neat 'decision points', involve various stages of deliberation, and are shaped by interaction with many (clinical and nonclinical) individuals.

- Informs a programme of work, Optimising Shared decision-maklng for high-Rlsk major Surgery, including development of a decision support intervention to improve shared decision making about elective major surgery.

\section{INTRODUCTION}

Shared decision making aims to bring patient values and preferences together with clinician expertise to determine the best care package for the individual concerned. It is not new, building on influential work published since the 1980s. ${ }^{1-3}$ The recent prominence given to shared decision making has accompanied a broader shift towards 'patient-centred care', along with a rise in patient advocacy and increased involvement in resource allocation. ${ }^{4-9}$ In the UK, following a landmark legal case, ${ }^{10}$ standards in respect of the consent process have shifted away from what a body of professionals deem relevant (paternalism) to what a reasonable patient would want or need to know (shared decision making). ${ }^{11-13}$

In surgery, shared decision making is espoused as an essential practice on the basis that it can improve patient satisfaction, moderate use of surgery and reduce costs. 
It is increasingly offered to older patients who are often (but not always) at higher risk of poor postoperative outcomes. Around 1.5 million major surgical procedures are now performed each year in the UK, ${ }^{14}$ with 250000 at high risk of postoperative complications. ${ }^{15}$ Even when surgery and anaesthesia are straightforward, one in three high-risk patients develops serious medical complications in the days following surgery. ${ }^{16}$ These complications delay recovery, with prolonged hospital stays and a decline in functional independence once patients return home. Critically, many high-risk patients never recover from these adverse effects, suffering significant reductions in long-term quality of life and survival. ${ }^{1617}$ For some, surgery is not the successful treatment they hoped for, with feelings of guilt or regret commonplace. ${ }^{18}$ Doctors recognise the need to help improve decision making for this patient group but often feel ill equipped to do so, ${ }^{19}$ with surgeons and anaesthetists currently lacking the expertise to make informed judgements about the risks such patients face. The problem is becoming more frequent as more patients living with severe chronic disease are offered surgical treatments. In sum, many people are having high-risk surgery (ie, major surgery with high-risk patients) and are sometimes regretting doing so, with this problem likely to increase.

Shared decision making is perceived as a potential means of addressing this but the impact of shared decision making is currently unclear. Three systematic reviews ${ }^{20-22}$ have shown that patients and clinicians generally value it and that it has potential to both improve the quality of decisions (largely via improved information sharing and increased knowledge ${ }^{21}$ ), and lessen conflict in decision making about preference-sensitive surgery (ie, where there is no one best available treatment). Overall reviews suggest that it is the quality of the decision making process, over the decision itself, that is key to improving outcomes. However, studies have tended to focus on a small number of clinical areas (eg, breast cancer, osteoarthritis); orient to decision making between the patient and physician alone; and assess outcomes allied to decision making rather than the process or experience per se (eg, of the 24 studies identified by Boss $e t a l,{ }^{21} 17$ measured outcomes on the effectiveness of the decision aid without directly assessing doctor-patient interactions). Few studies have linked surgical outcomes and decision-making processes, considered potentially relevant demographic characteristics (eg, age, socioeconomic status, ethnicity), or conducted follow-up to consider what decisions about surgery mean in the context of peoples' lives. Recently, some authors have called for a more multifaceted approach that further considers organisational and system level, as well as social and temporal, aspects of shared decision making including: relevant guidelines, workflows across the clinical team (eg, involving anaesthetists), the extended care pathway (eg, from preoperative assessment through to postoperative $\mathrm{de}$ /prescribing) and the influence of families. ${ }^{423-26}$

Interactions between clinicians and patients prior to making a decision about surgery are important (eg, we know that good communication is associated with increased professional and patient satisfaction ${ }^{27}$ ), but rarely the focus of research. To date, there has been limited research on communication between clinicians and patients in the context of shared decision making for surgery. What little there is has shown that communication practices often inadequately support preoperative shared decision making about surgery. Most (but not all) patients prefer to share in decision making but do not always have the chance to do so. ${ }^{8}$ Surgeons rarely employ a fully collaborative decision-making process, ${ }^{28} 29$ instead disclosing procedural risks and helping patients make choices by relying on standard practices (eg, informed consent) or communication practices such as the "fixit' model, describing the patient's disease as an isolated abnormality linked directly with a surgical solution. ${ }^{30}$

Of the literature on shared decision making for surgery, only a small number of North American studies focus on high-risk patients. ${ }^{31-34}$ Two have focused on how surgeons and patients discuss options in the event that postoperative complications are severe or life threatening. Analysis of audio recorded shared decision making encounters for high-risk surgery identified significant communication gaps regarding potentially severe postoperative complications. ${ }^{3133}$ Follow-up interviews revealed assumptions (on the part of patients and clinicians) that surgeons shared patients' values and expectations and would advise them accordingly, and that surgeons often regarded decisions about surgery as needing to be guided by their expertise and experience, over individual and preference-sensitive choice.

One study underscored the challenge for patients of incorporating their values and beliefs into shared decision making for high-risk surgery. ${ }^{32}$ Most patients agreed that surgery should only be considered when it could improve quality of life. However, when faced with a decision in a life-saving surgery scenario the majority chose surgery with likely subsequent functional impairment over palliation, citing lack of belief in the surgeon's prognosis ('there must be a better outcome available') and a feeling that 'choosing death' was unacceptable. Surgeons discussed the challenge of 'surgical momentum', that is, once a patient is on a pathway towards surgery the expectations of the patient and their family makes it hard to divert them away from a surgical intervention, even when they recognise the potential risk of severe postoperative complications. The language used, particularly the focus on 'fixing' a problem, was found to close down discussions about the value of surgery and how it may fit with patients' overall values and goals. ${ }^{35}$ To our knowledge, there are no published studies focused specifically on clinicians' perceptions of decision making for highrisk surgery, and why it may (or may not) be 'shared'. Research on the information needs of patients found a mismatch between what surgeons discussed in consultations and what patients wanted to know. ${ }^{27}$ In particular, patients wanted less technical information and more discussion of long-term effects. This resonates with recent 
legal judgements emphasising that, 'The doctor's duty is not fulfilled by bombarding the patient with technical information'. ${ }^{10}$

In sum, the literature on shared decision making for surgery is in its infancy, tends to focus on information giving, and employs quantitative assessments of the outcomes of decision making over qualitative understanding of processes and experiences. Studies relevant to surgery for high-risk patients are limited in number and suggest that high-risk patients often do not realise that they have a choice about surgery and have mismatched expectations about what may happen after surgery.

Research that enables understanding of shared decision making for high-risk patients is therefore timely and necessary. In this new study, we seek to identify perspectives on, and communicative features of, the shared decision making process for high-risk patients who are offered surgery asking:

1. How do patients, their families and clinical teams approach and negotiate decision making for major surgery?

2. Having had (or declined) major surgery, how do patients, their families and clinical teams reflect on the decisions they made?

\section{METHODS AND ANALYSIS}

\section{Origins, design and governance of the study}

The study forms part of a 6-year programme of work, Optimising Shared decision-makIng for high-RIsk major Surgery (OSIRIS, https: / / osiris-programme.org/) funded by the National Institute for Health Research in England. OSIRIS comprises four interlinked projects leading to the development and testing of a decision support intervention, to improve shared decision making about elective major surgery between doctors and patients at high risk of adverse long-term outcomes. The OSIRIS programme has significant governance oversight including a management group (see online supplementary file), a shadow steering committee, with patient and public membership and a lay chair, which meets 6 monthly and feeds into the main programme steering committee. An OSIRIS collaborators group includes stakeholders from National Health Service (NHS), professional bodies, academia, policy and patients.

In this study, we use qualitative methods to explore in-depth how patients, their families and clinicians negotiate decision making and reflect back on the decisions they made. The study involves a multidisciplinary team with representation from medicine, nursing, sociology, social policy and bioethics. Phase 1 involves videorecording decision making encounters about major surgery between patients, their carers/families and clinicians to understand the content and flow of decision making about surgery; followed by interviews (immediately after and 3-6 months later). Phase 2 involves focus groups with a wider group of patients and clinicians to test out emerging findings.

\section{Theoretical and conceptual framework}

Our research is framed by practice theory, recognising that decisions about surgery are distributed over time and space (ie, they rarely occur at single 'decision points'), ${ }^{36}$ involve varied stages of (potentially collaborative) deliberation ${ }^{37}$ and are shaped by interaction with a range of actors and artefacts. ${ }^{38}$ This guided us to focus on decision-making-in-action, seeing the process of decision making and the activities and events allied to it (eg, consultations, clinics, letters, family discussions), as something that happens through an ongoing process of communication and collaborative articulation of what major surgery might mean for those involved. We draw on ethnography of communication (an approach that aims to produce systematic and richly contextualised descriptions of communicative genres, events and practices ${ }^{39}$ ) to understand how meanings about surgery are constructed, the influence of moral and ethical dimensions and how communication and interaction unfold.

Finally, given that healthcare is heavily institutionalised, and behaviour often ritualised (ie, we know, and play out, the roles expected of us as clinicians, patients and so on), we draw on the notion of 'organisational routines', defined as 'recognisable, repetitive patterns of interdependent action carried out by multiple actors' ${ }^{41}$ Routines are how organisational life is patterned, hence studying these can provide key insights into how shared decision making may (or may not) be integrated into the three surgical areas of interest.

\section{Sampling and data collection}

Surgical areas

The OSIRIS programme focuses on three different (elective) surgical procedures: major joint, intra-abdominal and cardiac surgery. We plan to examine how the context of the differing conditions influences the decisions that patients and doctors make, how these decisions are made in the light of different ways of organising treatments and resources, and the multiple points at which patients and clinicians come together to consider and make decisions about surgery.

Major joint replacement for osteoarthritis is a symptomatic treatment which will not prolong life but can improve quality of life for those with significant pain and reduced mobility. It is likely to be considered and discussed within primary care, as well as specialist musculoskeletal services, as part of a potentially long-term process of considering surgery with an orthopaedic team. Colorectal surgery for bowel cancer is essential and requires relatively rapid decisions about treatment. Following diagnosis patients, relatives and clinicians are faced with choices about the nature of the procedure (including a potential for palliative surgery) and the need for adjunct radiotherapy or chemotherapy. Coronary artery bypass grafting may prolong life at a population level, but for the individual patient this benefit is not guaranteed, especially for frailer or multimorbid patients. Increasingly, less invasive, percutaneous coronary interventions have created a range of 
options for patients with ischaemic heart disease. There are, however, a range of short-term and long-term risks associated with both choices (eg, percutaneous options offer fewer short term risks to patients but have inferior long-term outcomes compared with surgery for more severe ischaemic heart disease).
Preliminary work with clinicians to map out the decision making processes across conditions and sites (figures 1-3) has highlighted variation in how services are organised (eg, variation in the anaesthetic preoperative assessment offered) and the distributed nature of decision making (ie, taking place over time, in multiple
Clinical processes

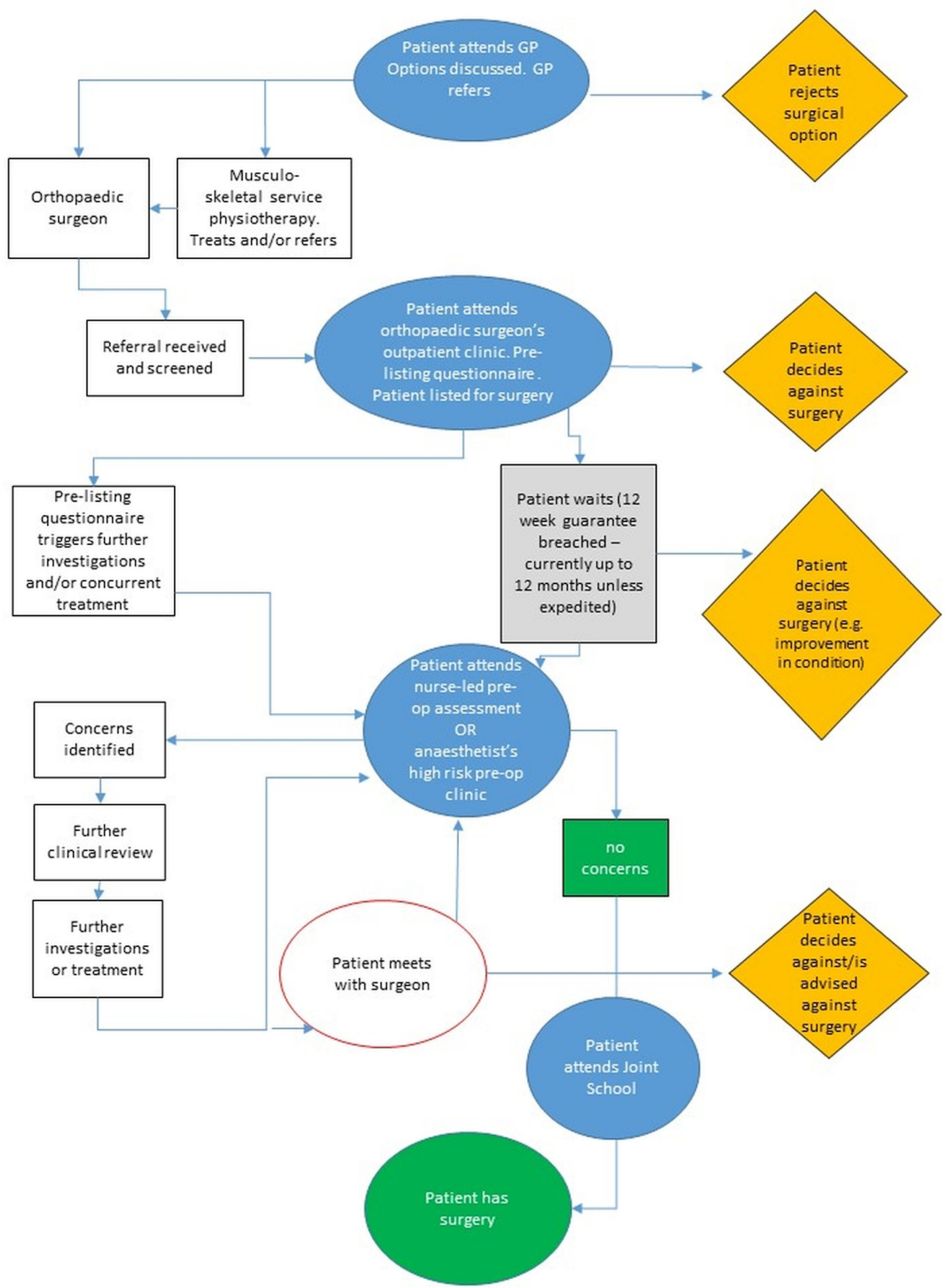

Figure 1 Example decision-making map for orthopaedic surgery. GP, general practitioner. 


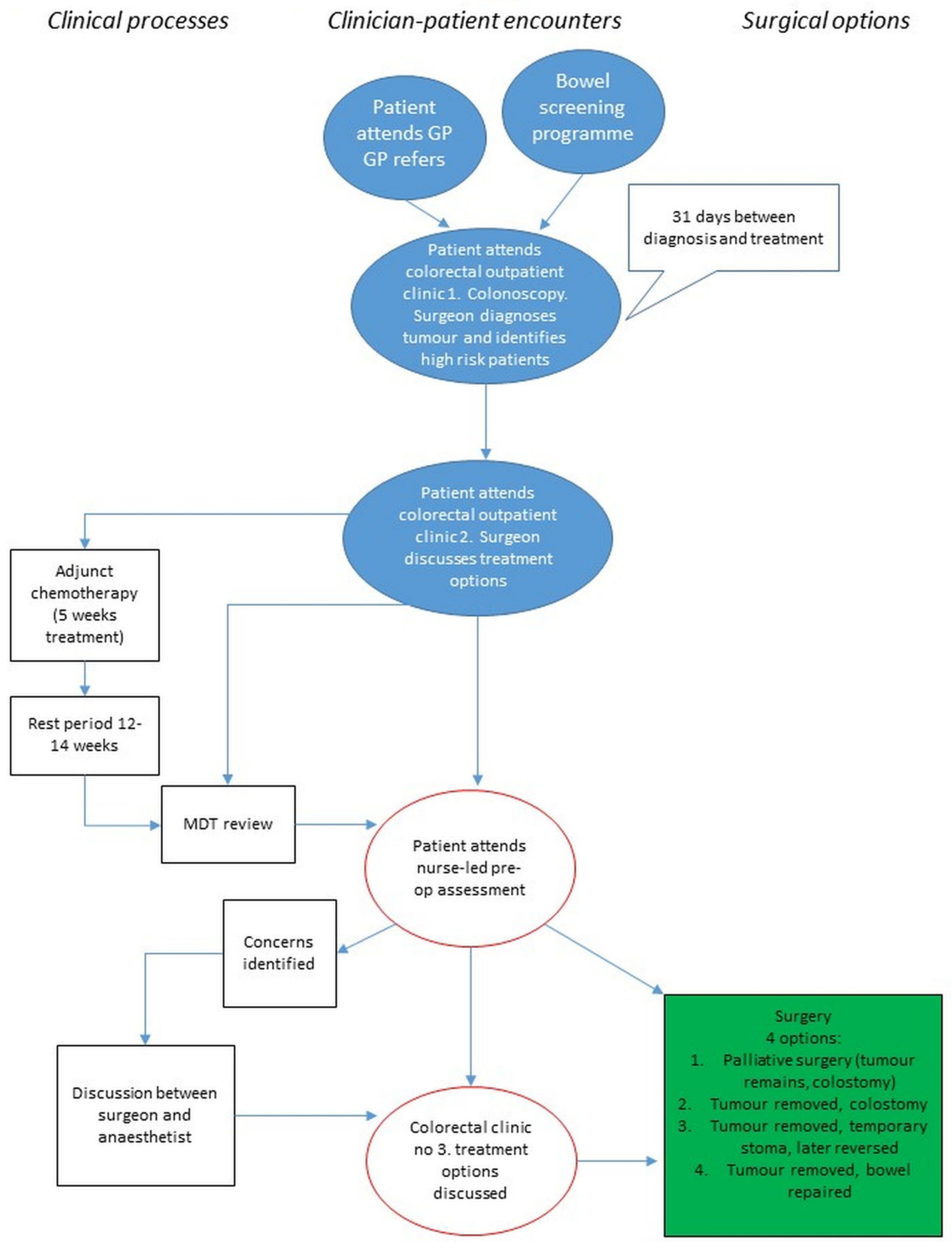

Figure 2 Example decision-making map for colorectal surgery. GP, general practitioner; MDT, multidisciplinary team.

settings, involving multiple discussions with, potentially, many people ${ }^{36}{ }^{37}$ ). This means that the process of decision making about elective surgery is likely to be different across the three surgical specialties of interest (see figures 1-3) and across settings. Our focus on high-risk patients due to age, chronic comorbidity, or frailty means that decision making is also likely to be influenced by past experiences (eg, prior surgery) and have a more complex combination of long-term outcomes to consider.
Phase 1: video recording of decision-making encounters, plus follow-up interviews

In phase 1, we will purposively select three NHS hospitals that are undertaking at least two of the three surgical procedures of interest. Working with clinical teams (who will receive basic study information) we will recruit a maximum variation, purposive-sample of 15 high-risk patients aged $\geq 60$ years (to capture a range of highrisk patients, not simply those who are older) with an 


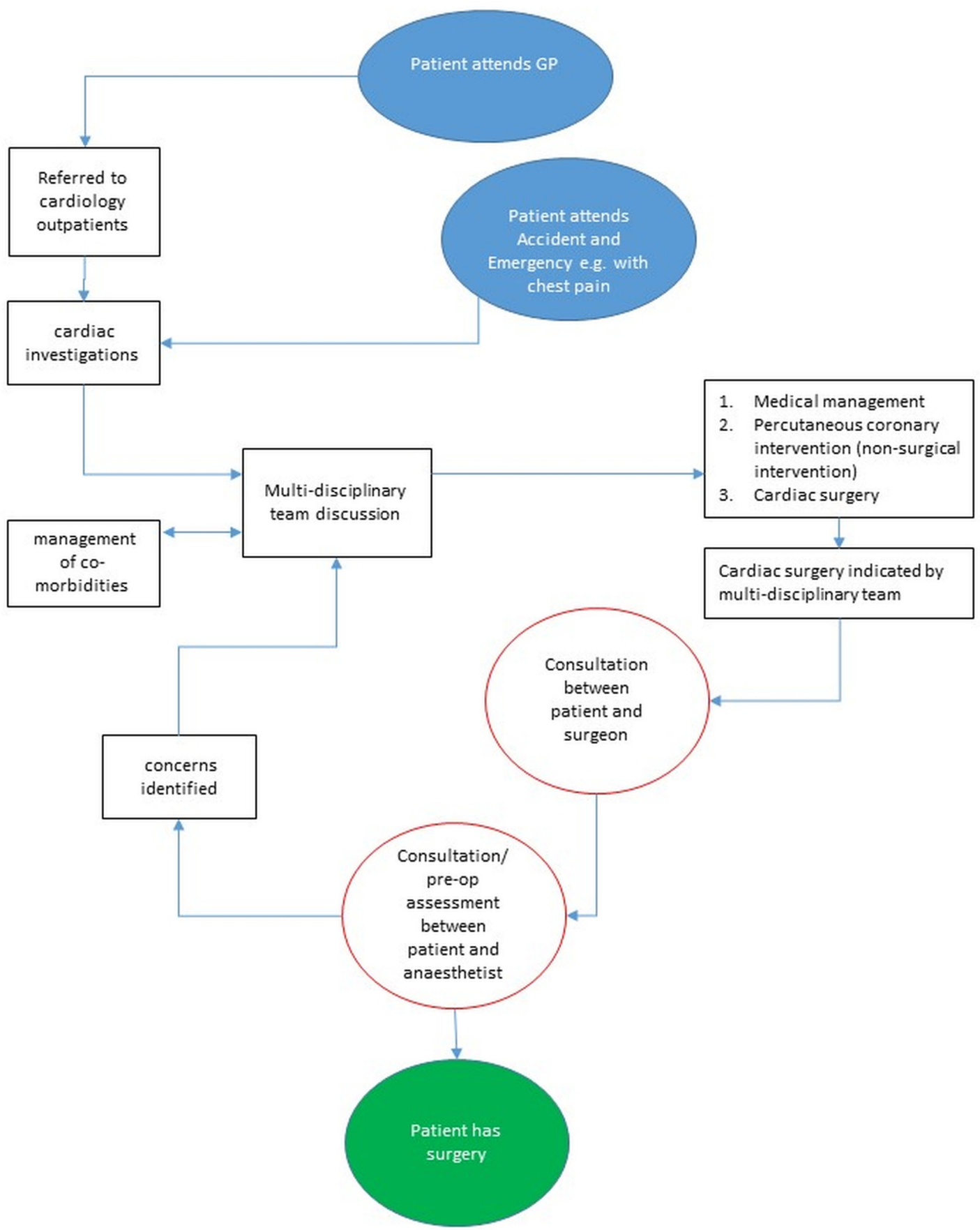

Figure 3 Example decision-making map for cardiac surgery. GP, general practitioner.

age-adjusted Charlson comorbidity score ${ }^{42}$ of $\geq 4$, who are contemplating elective surgery (anticipating five from each surgical group including, where feasible, one patient who has declined surgery), with adequate variation in age, gender and social circumstances and including travel time to the hospital.

We will video record up to 15 consultations that involve decision making about major surgery for those who agree to participate, seeking to capture verbal and non-verbal interaction, and enabling detailed insight into the decision making process in terms of the content of consultations (eg, information exchanged) and the interaction (eg, between clinician and patient). This will involve the researcher placing one or two video cameras in the consultation room and recording the consultation. Where the patient agrees, the researcher will remain in the room. This is usual in qualitative studies, with the researcher's presence enabling appreciation of each consultation as it unfolds in real time and the video recording facilitating detailed analysis of interaction that is not feasible through observation alone. 
Table 1 Overview of data structure and planned analysis

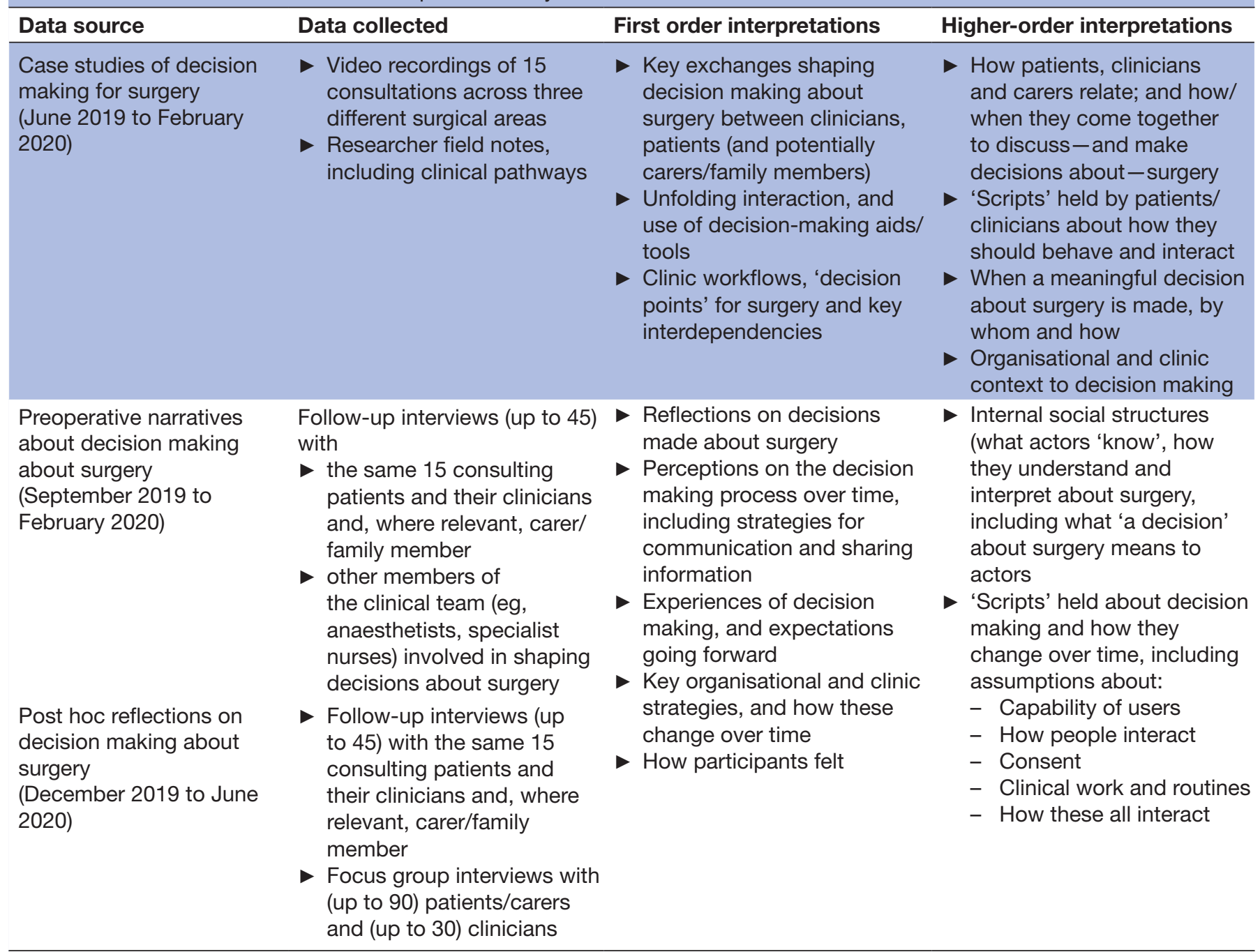

Pathways for major surgery vary (figures 1-3). We will not know how decision making processes unfold-and hence exactly which consultation we will record-until we have gained access to each site and clinical team. For some participants, the consultation that we record will be with their surgeon and will follow a series of contacts with the health service. For others, the consultation we record may be with another member of the clinical team (eg, anaesthetist) who has had a critical role in the decisionmaking process. Where decision making clearly spans several encounters, we will endeavour to record (or at the very least observe) more than one consultation.

We will subsequently conduct narrative interviews with patients and clinicians (and carers where relevant) at two points (table 1): as soon as practically possible after their consultation, and 3-6 months later. We will adopt a narrative approach, ${ }^{43}$ encouraging interviewees to recount the details of their experiences (eg, their condition, decision making about surgery). Interviews will last up to 1 hour, be face to face (wherever possible, by phone when not) and be audio recorded. Reimbursement will be offered for basic expenses (eg, car parking) incurred.
Interview data will enable a detailed understanding of the relevant condition, how it has unfolded, experiences of decision making and the context within which decisions were made, and thoughts and expectations about surgery (if this is the option chosen); as well as experiences since having or declining surgery, and reflections back on the decision made.

\section{Phase 2: focus groups}

Focus groups will allow us to test out emerging findings with a broader group of participants. We will purposively select up to 3 NHS hospitals (at least one of which will be different from phase 1) undertaking major joint surgery, intra-abdominal surgery and cardiac surgery, using the same criteria as phase 1 . We will recruit a purposive maximum variation sample of up to 90 high-risk patients (up to nine focus groups), excluding any patients recruited in phase 1 , who have undergone or declined surgery in one of these areas in the past 12 months and ensuring a mix of age, gender, social circumstances and surgical outcomes. Where patients with severe complications are unable to participate, we will invite them to 
nominate someone who can represent their views and/or have a carer attend with them.

Working with Royal Colleges, we will also recruit a purposive sample of up to 30 surgeons, doctors, anaesthetists and clinical nurse specialists (up to 3 focus groups) caring for patients having these types of surgery, ensuring a mix of age, gender, clinical position and experience, role and location. We will hold at least one focus group involving a mix of professional groups.

Focus groups with patients and carers will be held at or close by (eg, local community centre) to participating sites, involve 8-10 participants in each. Those involving clinicians will be held at central locations (eg, one of the Royal Colleges). The same topic guide will be used across groups, guiding participants to introduce themselves and say what their experience is of making decisions (or supporting others to make decisions) about major surgery. We plan to ask patients, carers and clinicians to share thoughts on the draft scenarios (ie, 3-5 summary descriptions of decision making) developed from phase 1. Focus groups will be audio recorded and transcribed.

\section{Analysis and synthesis}

Table 1 summarises different data sources and how these will be analysed and synthesised to provide detailed decision-making scenarios and inform the wider OSIRIS programme.

In phase 1, we will develop summaries for each case (ie, patient, family/carers and clinicians), detailing how their condition developed and led them to access services, the process of gaining a diagnosis and discussing possible surgery, the exchange of information about surgery (including relevant national and international guidelines) and expectations allied to that, reflections on risk, the involvement of others in decision making about surgery, the experience of surgery and postoperative care or of living with the condition having declined surgery; as well as post hoc reflections on decision making in light of outcomes following surgery or the decision to decline.

We will supplement this with detailed analysis of decision making encounters. Video recordings provide a powerful dataset for analysis, allowing us to zoom in and slow down the decision making process to examine interactions, judgements and interpretations, ${ }^{44}$ the bodily conduct of participants, and the ways in which objects (eg, consent forms) come to gain significance at particular moments. ${ }^{45}$ Recordings will be transcribed (eg, using ELAN, a specialist programme used by linguists) to allow us to capture granular (verbal and non-verbal) detail of interaction, repeatedly view and tag data digitally (ensuring immersion in the full video and audio at the level of a sentence, comment or other linguistic feature, which is often key to analysis ${ }^{45}$ ), and produce a textual transcript meaning that we can engage indirectly with the data via transcripts of each decision making encounter.

We will then examine video data in depth to: identify key features of shared decision making encounters, examine the way "communicative competence" ${ }^{46}$ shapes shared decision making (ie, how participants deploy their tacit understanding of a particular communicative event, and competencies needed to maximise the benefits of the encounter), and attend to the contextual factors (eg, presence of carers, preceding exchange of information) that shape decision making. Analysis of interaction will be informed by ethnography of communication (see above) and guided by established techniques developed for the microanalysis of face-to-face interaction. The issues that are likely to repay close analysis include: openings (how participants initially frame the consultation); the use of questions (eg, whether and how patients as well as clinicians use them) and, the expression of affect (particularly when clinicians need to communicate complicated or sensitive information).

We will synthesise data from phase 1 into vignettes, drawing on video recordings to understand communication and interaction, and on interviews and field notes to understand the clinical, organisational, material and cultural context in which shared decision making takes place. Guided by existing theory (see above) we will compare and contrast across vignettes to examine similarities and differences in decision making, paying particular attention to the ways in which participants seek to achieve constructive interpersonal engagement, recognition of alternative actions, comparative learning, preference construction and elicitation, and preference integration (ie, the key components of Collaborative Deliberation $^{37}$ ). Finally, we will develop 3-5 draft decision-making scenarios, emerging from identification of patterns in our emerging analysis about how decision making variably unfolds among different groups, in different settings and for different kinds of surgery; as well as the extent to which this might be regarded as 'shared'.

We will use thematic and comparative analysis ${ }^{47}$ to analyse focus group data, generating a detailed understanding of the choices that patients, families/carers and clinicians make about surgery and the factors that shape decision making. We will revise decision making scenarios in light of wider consensus (or challenge) about the importance placed on short-term, medium-term and long term outcomes after different types of surgery (or no surgery). Finally, we will synthesise analyses across our datasets, seeking to extend current theory on decision making for high-risk patients offered surgery (table 1).

\section{Patient and public involvement}

We are committed to patient and public involvement in all stages of the research. Patients with lived experience of major surgery are included in the OSIRIS programme leadership and steering committee. A patient panel has already been established, providing patients with the space to discuss the research, and feed directly into the main steering committee. Patients will be invited to participate in workshops early in the programme to refine our research design, guide the team on how best to approach sensitive topics with patients, and help to refine research tools (eg, topic guides). Later in the OSIRIS programme 


\begin{tabular}{|c|c|c|}
\hline & Planned outputs & Anticipated impact \\
\hline $\begin{array}{l}\text { Phase } 1 \\
\text { Video recording of } \\
\text { consultations, plus } \\
\text { interviews }\end{array}$ & $\begin{array}{l}15 \text { detailed vignettes of decision making for high- } \\
\text { risk surgery } \\
3-5 \text { draft decision-making scenarios, summarising } \\
\text { patient pathways and decision making }\end{array}$ & $\begin{array}{l}\text { Increased understanding (within and beyond OSIRIS) } \\
\text { of the process of decision making. } \\
\text { Identification of the long-term outcomes that matter } \\
\text { most to patients contemplating major surgery }\end{array}$ \\
\hline $\begin{array}{l}\text { Phase } 2 \\
\text { Focus groups with } \\
\text { patients, carers } \\
\text { and clinicians }\end{array}$ & $\begin{array}{l}\text { Typology of decision-making scenarios } \\
\text { Exemplar vignettes and videos (with consent) } \\
\text { providing insights into decision making for high-risk } \\
\text { surgery } \\
\text { Research publications and presentations, plus } \\
\text { accessible summaries of key findings } \\
\text { Leaflet and web download for patients and families. }\end{array}$ & $\begin{array}{l}\text { Inform codesign, with patients and doctors, of a } \\
\text { decision support intervention to be tested in a clinical } \\
\text { trial } \\
\text { Refined theory of shared decision making relevant to } \\
\text { high-risk surgical patients } \\
\text { Improved guidance for clinicians, patients and } \\
\text { providers } \\
\text { Increased understanding of what to expect when } \\
\text { making a decision about major surgery. }\end{array}$ \\
\hline
\end{tabular}

OSIRIS, Optimising Shared decision-makIng for high-RIsk major Surgery.

these patient networks will help to co-design a decision support intervention. Patient coapplicants will act as coauthors for scientific and lay reports.

\section{ETHICS AND DISSEMINATION}

The research has received ethical approval from South Central Oxford C Research Ethics Committee (19/ $\mathrm{SC} / 0043)$. At the time of writing, we have recruited all three sites and gained local governance approval.

An important ethical issue relates to the involvement of patients (and by extension family/carers) at a time when they might be feeling emotionally and physically vulnerable and needing to make potentially life-changing decisions. We have sought to address this by ensuring that recruitment/consent is as straightforward as possible, framing questions about care and experiences of surgery sensitively, and inviting patients (should they wish) to involve family members or other carers in interviews. Working closely with clinical teams, we will be sensitive to the different clinical pathways and the ways in which information and diagnoses are shared with patients, and have planned an observation period with each site in phase 1 to appreciate the referral and decision-making process about major surgery before recruiting patients.

We plan dissemination within and outside of the OSIRIS programme (table 2). For the former, we will produce a typology of decision-making scenarios for major surgery. Combined with research to determine what happens to patients during the years after surgery, this will inform the co-design of a decision support intervention to be tested in a clinical trial. For the latter, we will produce research publications and presentations for academics, including a refined theory of shared decision making relevant to high-risk patients in the context of surgery. For service providers, policy-makers and regulators, we propose succinct and accessible summaries of key findings including summaries of decision making scenarios and provisional operational guidance. For patients and families/carers, we will produce a leaflet and web download summarising findings and setting out what to expect when making a decision about major surgery.

Availability of video data holds potential for further research and training about shared decision making (table 2). In future, we plan to work with colleagues in the OSIRIS programme and more widely to provide rich and detailed accounts of shared decision making in practice and inform practice.

Author affiliations

${ }^{1}$ Nuffield Department of Primary Care Health Sciences, University of Oxford, Oxford, UK

${ }^{2}$ School of Medicine \& Dentistry, Queen Mary University of London, London, UK ${ }^{3}$ Barts and the London School of Medicine \& Dentistry, Queen Mary University of London, London, UK

${ }^{4}$ School of Law, City University of London, London, UK

${ }^{5}$ Department of Anaesthesia, St. George's University Hospitals Foundation Trust, London, UK

${ }^{6}$ Department of Anaesthesia, John Radcliffe Hospital, Oxford, UK

${ }^{7}$ Department of Anaesthesia, Royal Alexandra Hospital, Paisley, UK

${ }^{8}$ Patient Representative, Leeds, UK

Twitter Sara Shaw @SaraShawX2 and Gemma Hughes @GemHughes

Contributors SS conceptualised the study and wrote the first draft of the paper GH and TS contributed to study design and will be collecting and analysing data across the study. JD, JE, EA and ME have contributed to understanding surgical pathways, developing decision-making maps (figures 1-3) and approaches to recruitment into the study. REA has contributed to theoretical approach, particularly on decision making. RP and JP are codirectors of the OSIRIS programme, of which this study is part and which the OSIRIS Programme Group oversees. LE is lay chair of the OSIRIS shadow steering group. Both the OSIRIS Programme Group and shadow steering group have fed into the design and conduct of the study. All authors had input to revisions of the paper and approved the final manuscript.

Funding The OSIRIS Programme is supported by the National Institute of Health Research (grant number RP-PG-0218-20001). SS is also supported via the National Institute for Health Research Biomedical Research Centre, Oxford (grant number BRC-1215-20008) to the Oxford University Hospitals NHS Foundation Trust and the University of Oxford.

Disclaimer The views expressed are those of the author(s) and not necessarily those of the NIHR or the Department of Health and Social Care.

Competing interests RP has received research grants and/or honoraria from Edwards Lifesciences, Intersurgical, BBraun and GlaxoSmithkline. 
Patient and public involvement Patients and/or the public were involved in the design, or conduct, or reporting, or dissemination plans of this research. Refer to the Methods section for further details.

Patient consent for publication Not required.

Provenance and peer review Not commissioned; externally peer reviewed.

Open access This is an open access article distributed in accordance with the Creative Commons Attribution Non Commercial (CC BY-NC 4.0) license, which permits others to distribute, remix, adapt, build upon this work non-commercially, and license their derivative works on different terms, provided the original work is properly cited, appropriate credit is given, any changes made indicated, and the use is non-commercial. See: http://creativecommons.org/licenses/by-nc/4.0/.

\section{ORCID iDs}

Sara Shaw http://orcid.org/0000-0002-7014-4793

Gemma Hughes http://orcid.org/0000-0003-2930-1125

Richard Edmund Ashcroft http://orcid.org/0000-0001-6065-4717

\section{REFERENCES}

1 Katz J. The silent world of doctor and patient. Balimore, MD: John Hopkins University Press, 1984.

2 Charles C, Gafni A, Whelan T. Decision-making in the physicianpatient encounter: revisiting the shared treatment decision-making model. Soc Sci Med 1999;49:651-61.

3 Coulter A, Collins A. Making shared decision making a relaity: no decision about me wihtout me. London: King's Fund, 2011.

4 Sturgess J, Clapp JT, Fleisher LA. Shared decision-making in perioperative medicine: a narrative review. Anaesthesia 2019;74 Suppl 1:13-19.

5 Mongan D, Long J, Farragher L. Models of patient advocacy: evidence brief. Dublin: Health Research Board, 2016.

6 Epstein RM, Street RL. The values and value of patient-centered care. Ann Fam Med 2011;9:100-3.

7 Committee on Quality of Health Care in America. Institute of medicine: crossing the quality chasm: a new health system for the 21st century. Washington, DC: National Academy Press, 2001.

8 Institute of Medicine. Dying in America: improving quality and honoring individual preferences near the end of life. Washington, DC: The National Academies Press, 2015.

9 Choosing Wisely. Available: https://www.choosingwisely.org/

10 Montgomery (Appellant) v Lanarkshire Health Board (Respondent) [2015] UKSC11 on appeal from [2013] CSIH 3.

11 General Medical Council. Good medical practice. London: GMC, 2013.

12 Department of Health. NHS constitution: the NHS belongs to us all. London: Department of Health, 2015.

13 Key W, Stwart M. Guidelines for the provision of anaesthesia services. London: Royal College of Anaethetists, 2016.

14 Abbott TEF, Fowler AJ, Dobbs TD, et al. Frequency of surgical treatment and related Hospital procedures in the UK: a national ecological study using Hospital episode statistics. Br J Anaesth 2017;119:249-57.

15 Pearse RM, Moreno RP, Bauer P, et al. Mortality after surgery in Europe: a 7 day cohort study. Lancet 2012;380:1059-65.

16 International Surgical Outcomes Study group. Global patient outcomes after elective surgery: prospective cohort study in 27 lowmiddle- and high-income countries. Br J Anaesth 2016;117:601-9.

17 Khuri SF, Daley J, Henderson W, et al. The Department of Veterans Affairs' NSQIP: the first national, validated, outcome-based, riskadjusted, and peer-controlled program for the measurement and enhancement of the quality of surgical care. National Va surgical quality improvement program. Ann Surg 1998;228:491-507.

18 Doherty C, Saunders MNK. Elective surgical patients' narratives of hospitalization: the co-construction of safety. Soc Sci Med 2013;98:29-36.

19 Bougeard A-M, Brent A, Swart M, et al. A survey of UK peri-operative medicine: pre-operative care. Anaesthesia 2017;72:1010-5.

20 de Mik SML, Stubenrouch FE, Balm R, et al. Systematic review of shared decision-making in surgery. Br J Surg 2018;105:1721-30.

21 Boss EF, Mehta N, Nagarajan N, et al. Shared decision making and choice for elective surgical care: a systematic review. Otolaryngol Head Neck Surg 2016;154:405-20.
22 Joseph-Williams N, Elwyn G, Edwards A. Knowledge is not power for patients: a systematic review and thematic synthesis of patientreported barriers and facilitators to shared decision making. Patient Educ Couns 2014;94:291-309.

23 Clapp JT, Arriaga AF, Murthy S, et al. Surgical consultation as social process: implications for shared decision making. Ann Surg 2019;269:446-52.

24 Scholl I, LaRussa A, Hahlweg P, et al. Organizational- and systemlevel characteristics that influence implementation of shared decision-making and strategies to address them - a scoping review. Implement Sci 2018;13:40.

25 Müller E, Hahlweg P, Scholl I. What do stakeholders need to implement shared decision making in routine cancer care? A qualitative needs assessment. Acta Oncol 2016;55:1484-91.

26 King E, Taylor J, Williams R. Vanson: the magic programme: evaluation. an independent evaluation of the magic (making good decisions in collaboration) improvement programme. London: Health Foundation, 2013.

27 McNair AGK, MacKichan F, Donovan JL, et al. What surgeons tell patients and what patients want to know before major cancer surgery: a qualitative study. BMC Cancer 2016;16:258.

28 Braddock C, Hudak PL, Feldman JJ, et al. "Surgery is certainly one good option": quality and time-efficiency of informed decisionmaking in surgery. J Bone Joint Surg Am 2008;90:1830-8.

29 Kruser JM, Pecanac KE, Brasel KJ, et al. "And I think that we can fix it": mental models used in high-risk surgical decision making. Ann Surg 2015;261:678-84.

30 Taylor LJ, Rathouz PJ, Berlin A, et al. Navigating high-risk surgery: protocol for a multisite, stepped wedge, cluster-randomised trial of a question prompt list intervention to empower older adults to ask questions that inform treatment decisions. BMJ Open 2017;7:e014002.

31 Pecanac KE, Kehler JM, Brasel KJ, et al. It's big surgery: preoperative expressions of risk, responsibility, and commitment to treatment after high-risk operations. Ann Surg 2014;259:458-63.

32 Nabozny MJ, Kruser JM, Steffens NM, et al. Constructing Highstakes surgical decisions: it's better to die trying. Ann Surg 2016;263:64-70.

33 Nabozny MJ, Kruser JM, Steffens NM, et al. Patient-Reported limitations to surgical Buy-in: a qualitative study of patients facing high-risk surgery. Ann Surg 2017;265:97-102.

34 Steffens NM, Tucholka JL, Nabozny MJ, et al. Engaging patients, health care professionals, and community members to improve preoperative decision making for older adults facing high-risk surgery. JAMA Surg 2016;151:938-45.

35 Fovargue S, Miola J. One step forward, two steps back? The GMC, the common law and 'informed' consent. J Med Ethics 2010;36:494-7.

36 Rapley T. Distributed decision making: the anatomy of decisions-inaction. Sociol Health IIIn 2008;30:429-44.

37 Elwyn G, Lloyd A, May C, et al. Collaborative deliberation: a model for patient care. Patient Educ Couns 2014;97:158-64.

38 Feldman MS, Orlikowski WJ. Theorizing practice and practicing theory. Organization Sci 2011;22:1240-53.

39 Gumperz J, Hymes D. Directions in Sociolinguistcs: the ethnography of communication. New York: Basil Blackwell, 1972.

40 Feldman MS, Pentland BT. Reconceptualizing organizational Routines as a source of flexibility and change. Adm Sci $Q$ 2003;48:94-118.

41 Feldman MS, Pentland BT, D'Adderio L, et al. Beyond Routines as things: introduction to the special issue on routine dynamics. Organization Sci 2016;27:505-13.

42 Charlson M, Szatrowski TP, Peterson J, et al. Validation of a combined comorbidity index. J Clin Epidemiol 1994;47:1245-51.

43 Greenhalgh T, Russell J, Swinglehurst D. Narrative methods in quality improvement research. Qual Saf Health Care 2005;14:443-9.

44 Bezemer J, Cope A, Korkiakangas T, et al. Microanalysis of video from the operating room: an underused approach to patient safety research. BMJ Qual Saf 2017;26:583-7.

45 Pearce C. Doctors, patients and computers, the new consultation (PHD thesis). Melbourne, Australia: Department of General Practice, The University of Melbourne, 2007.

46 Hymes D. On communicative competence. In: Pride JB, Holmes J, eds. Socolinguistics: selected readings. Harmondsworth: Penguin, 1972: 269-93.

47 Miles M, Huberman M, Saldana J. Qualitative data analysis: a methods Sourcebook. London: Sage, 2014. 